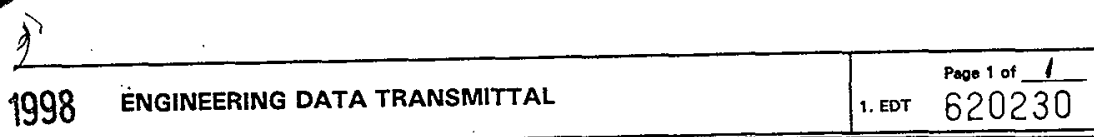

ving Organization)

- haracterization Engineering

5. Proj./Prog./Dept./Div.:

Characterization Project

8. Originator Remarks: $9 / 25 / 98$

THIS EGA TRANSMITS THE DATA LISTED IN BLOCK 15 FOR REVIEW AND ÅPPROVAL PREPARATORY TO RELEASE.

3. From: (Originating Organization)

Characterization Engineering

6. Design Authority/Design Agent/Cog. Engr.:

GP Janicek/BL Coverdell/RN. Dale

11. Receiver Remarks:
11A. Design Baseline Document? [X]Yes [] No

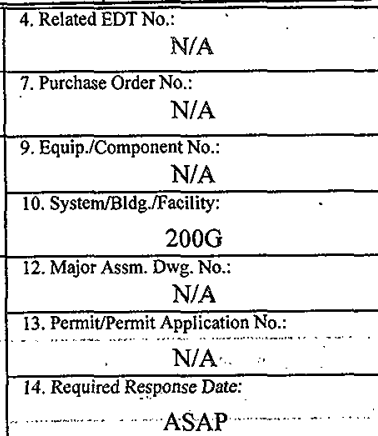

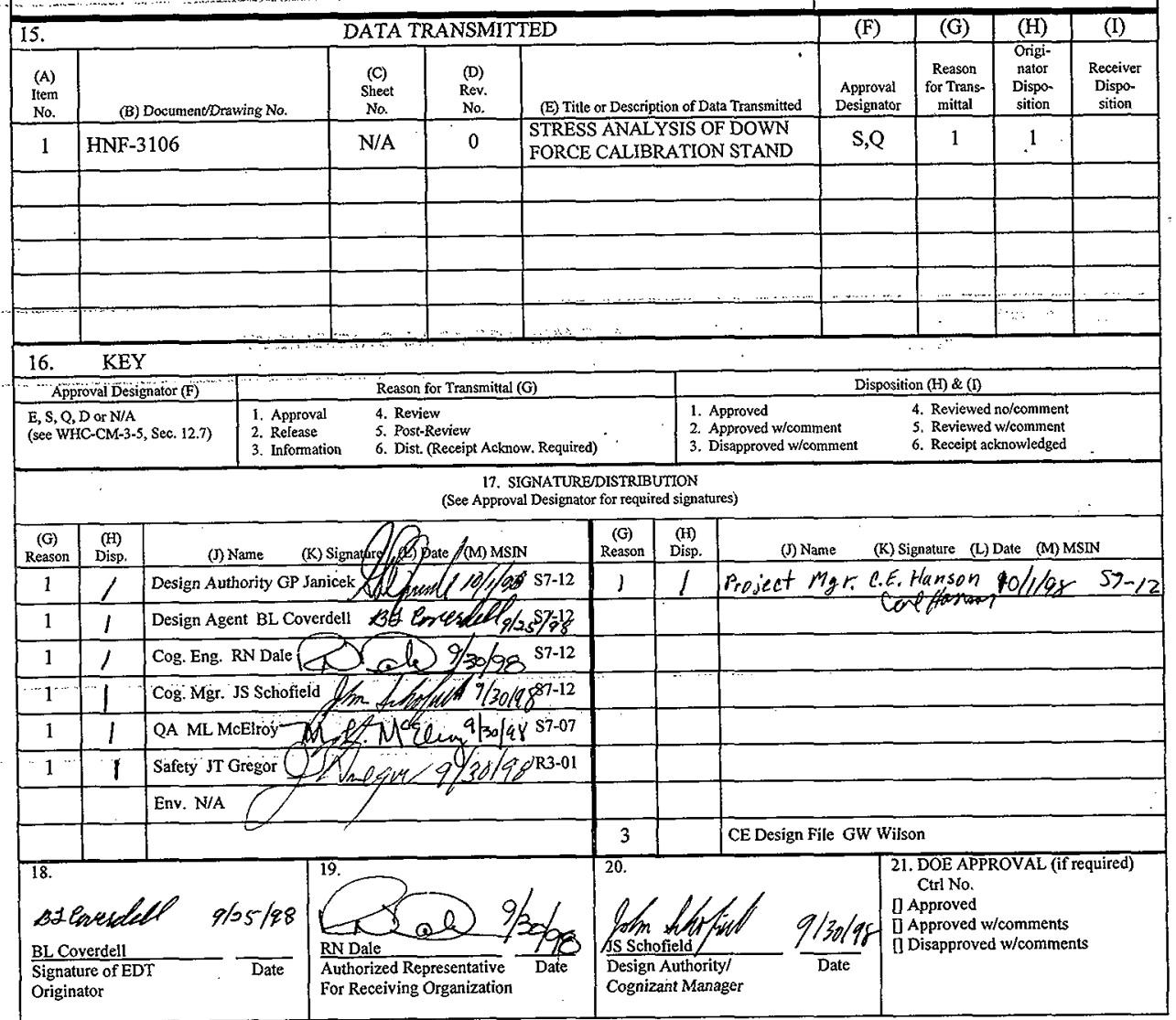

BD-7400-172-2 (05/96) GEF097 


\title{
Stress Analysis of Down Force Calibration Stand
}

\author{
B. L. Coverdell \\ COGEMA Engineering Corporation . \\ 1200 Jadwin \\ Richland, WA 99352 \\ U.S. Department of Energy Contract DE-AC06-96RL13200 \\ EDT/ECN: 620230 UC: 2070 \\ Org Code: 08E00 Charge Code: N4J2C \\ B\&R Code: EW3120074 Total Pages: 18
}

Key Words: Calibration, Rotary Mode Core Sample Truck (RMCST), Down Force, Drill String, Drill Rig

Abstract: This document presents the stress analysis of the Down Force Calibration Stand. All structural components were evaluated and found to be adequate to withstand the applicable design loads meeting all codes and standards requirements.

TRADEMARK DISCLAIMER. Reference herein to any specific commercial product, process, or service by trade name, trademark, manufacturer, or otherwise, does not necessarily constitute or imply its endorsement, recommendation, or favoring by the United States Government or any agency thereof or its contractors or subcontractors.

Printed in the United States of America. To obtain copies of this document, contact: Document Control Services, P.O. Box 950, Mailstop H6-08, Richland WA 99352, Phone (509) 372-2420; Fax (509) 376-4989.
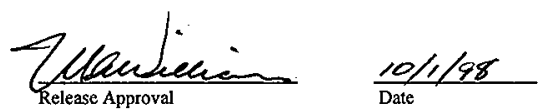

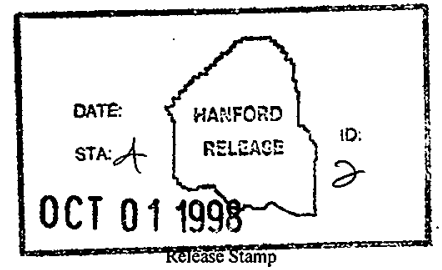

\section{Approved for Public Release}




\title{
STRESS ANALYSIS OF THE DOWN FORCE CALIBRATION STAND
}

\author{
B. L. Coverdell \\ COGEMA ENGINEERING CORPORATION
}

July 22, 1998 


\section{CHECKLIST FOR INDEPENDENT REVIEW}

Document Reviewed: STRESS ANALYSIS OF DOWN FORCE CALIBRATION STAND

Author: B. L. Coverdell

Yes No N/A

X] [ ] [ ] Problem completely defined.

[x] [ ] [ ] Necessary assumptions explicitly stated and supported.

[ ] [ ] [X] Computer codes and data files documented.

[y] [ ] [ ] Data used in calculations explicitly stated in document.

M [ ] [ ] Data checked for consistency with original source information as applicable.

M [ ] [ ] Mathematical derivations checked including dimensional consistency of results.

W [ ] [ ] Models appropriate and used within range of validity or use outside range of established validity justified.

W [ ] [ ] Hand calculations checked for errors.

[ ] [ ] [X Code run streams correct and consistent with analysis documentation.

[ ] [ ] $\$ Code output consistent with input and with results reported in analysis documentation.

M [ ] [ ] Acceptability limits on analytical results applicable and supported. Limits checked against sources.

W [ ] [ ] Safety margins consistent with good engineering practices.

W [ ] [ ] Conclusions consistent with analytical results and applicable limits.

A [ ] [ ] Results and conclusions address all points required in the problem statement.

Reviewer:

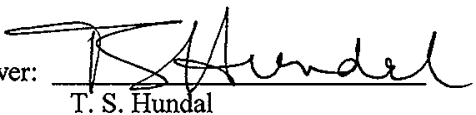

Date: $9 / 25 / 98$ 


\section{DESIGN VERIFICATION METHOD}

The need for design verification has been reviewed with the method selected as indicated below: (Work Plan \#NA /

$\mathrm{x}$ Independent Review

Alternate Calculations

Qualification Testing

Formal Design Review

$\begin{array}{ll}R N \text { Dale } & \text { Bfe } \\ \text { G/25/98 }\end{array}$

GP Janicek / BL Coverdell / OS Itaring

Design Authority / Design Agent / Cog. Engr.

DOC \#HNF-3106, Rev. 0

ECN\#_NA

DWG(S) \#H-2-690124 


\section{TABLE OF CONTENTS}

1.0 INTRODUCTION

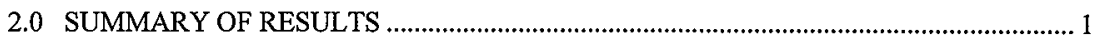

3.0 DISCUSSION

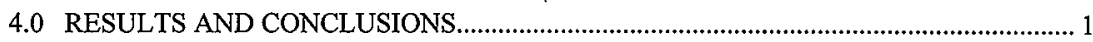

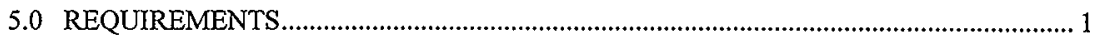

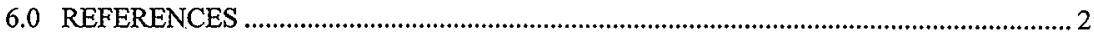

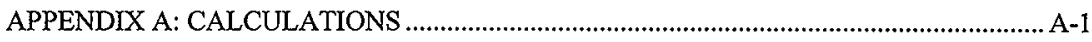




\subsection{INTRODUCTION}

This analysis evaluates the structural adequacy of the Down Force Calibration Stand (DFCS). The DFCS will be used to safely calibrate the electronic and mechanical components used in determining the down force applied by a Core Sample Truck (CST) drill rig.

\subsection{SUMMARY OF RESULTS}

The calculations determined the overall weight of the DFCS (approx. $200 \mathrm{lb}$.) and that the DFCS is adequate to support the $5,700 \mathrm{lb}$. down force applied by a CST drill rig.

\subsection{DISCUSSION}

Currently, a steel spring type DFCS is used to calibrate the down force of a CST drill rig. This type of DFCS has been deemed unsatisfactory and unsafe for use. The new DFCS uses an air spring instead of four steel springs. The air spring is allowed to move in the vertical direction by the use of four hardened steel rods and ball bushing bearings. The drill string thrusts against an aluminum push block. This block then rests on a thrust bearing which allows the drill string to rotate.

The air spring in conjunction with the bushing bearings and rods will provide a more stable platform for down force and it will also provide a safer means of calibration.

\subsection{RESULTS AND CONCLUSIONS}

The calculations in Appendix A determined that the DFCS is adequate to support the $5,700 \mathrm{lb}$. down force applied by the hydraulic rams on a CST.

\subsection{REQUIREMENTS}

Following are the only requirements for use of the DFCS:

1) For the $0 \mathrm{lb}$. to $1000 \mathrm{lb}$. load test the air spring must be inflated just enough to support the upper pillow block plate and the parts attached to it.

2) For the $4000 \mathrm{lb}$. to $5700 \mathrm{lb}$. load test the air spring should be inflated to approximately 58 psi.

3) The DFCS must be placed on a solid surface such as concrete or plywood.

4) The solid surface must not be out of level by more than 5 degrees.

5) The DFCS must be leveled using the four swivel pads mounted on threaded rod.

The air spring inflation pressure requirements ensures that the air spring will resist down force of the CST hydraulic rams and allow the maximum stroke. The solid surface requirement ensures that the DFCS will remain in a stable upright position. The 5 degree level requirement ensures that the four swivel pads will be used to keep the DFCS level. Keeping the DFCS level ensures that no horizontal loads will be applied and failure due to bending or buckling of the rods will not occur. 


\subsection{REFERENCES}

AISC, 1989, Manual of Steel Construction, ninth Edition, American Institute of Steel Construction, Chicago, Illinois.

Kleinlogel, A, 1956, Rigid Frame Formulas, Fredrick Ungar Publishing Co., New York.

Oberg, E. and Jones, F.D., Machinery's Handbook, $25^{\text {th }}$ Edition, Industrial Press Inc., New York. 
HNF-3106, Rev. 0

Appendix A

Appendix A

Calculations

A-1 
HNF-3106, Rev. 0

Appendix A

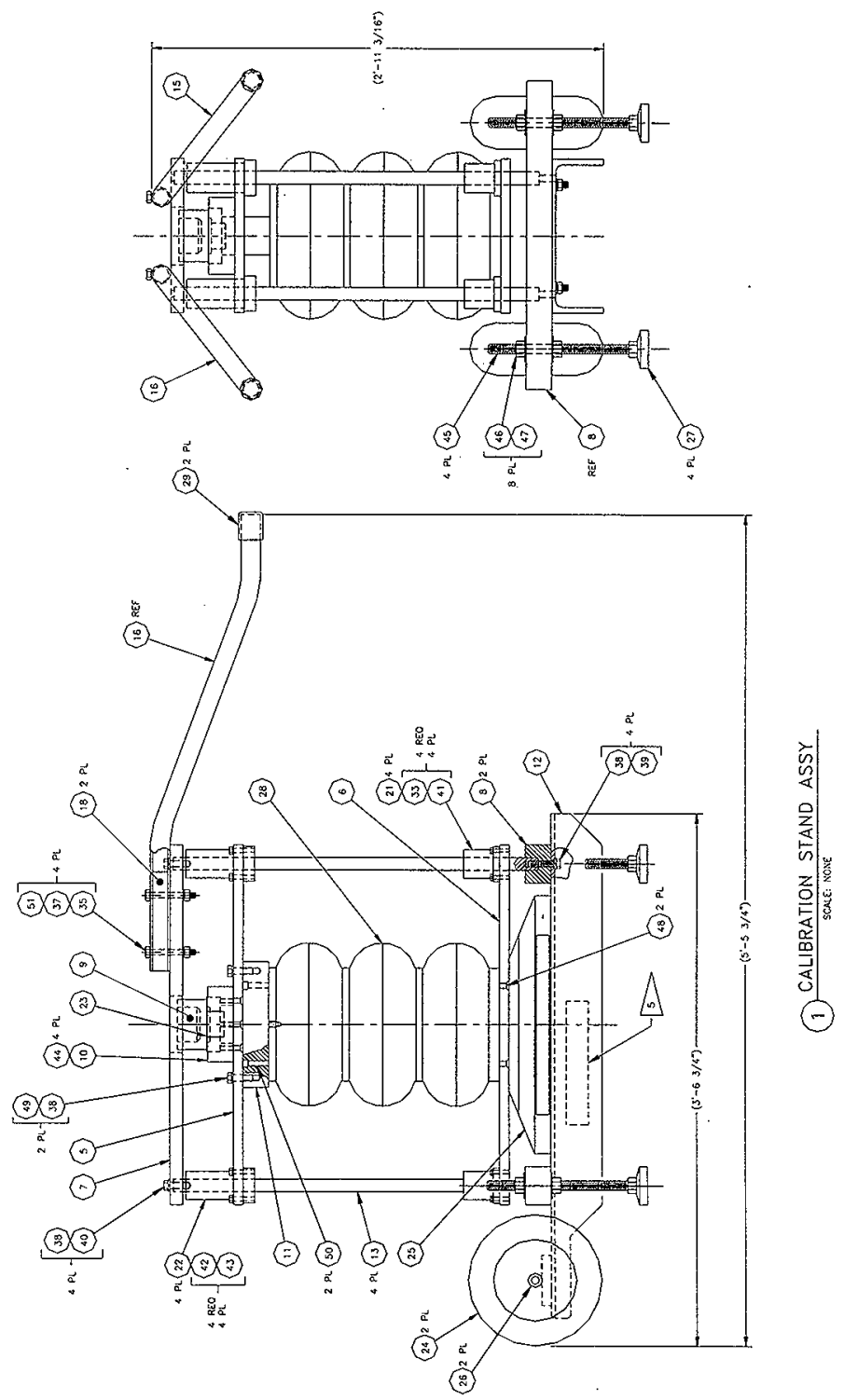


HNF-3106, Rev. 0

Appendix A

\section{COGEMA Engineering Corp.}

Calc. No.

Revision

Page No.
Client:_Characterization Equipment Subject: Down Force Calibration Stand

Location:
DESIGN ANALYSIS

WOIJob No.

Date: $\quad 4 / 15 / 98$

Checked:

Revised:
By: B. L. Coverdell

By:

1.0

\section{OBJECTIVE}

Determine the structural adequacy of the Down Force Calibration Stand.

2.0

\section{DESIGN INPUTS}

2.1 Drawing $(\mathrm{H}-2-690124)$.

3.0 ASSUMPTIONS

$3.1 \quad$ None

4.0 METHODS OF ANALYSIS Hand Calculations

5.0

5.1 AlSC, 1989, Manual of Steel Construction, 9th Edition, American Institute of Steel Construction, Chicago litinois.

5.3 Oberg, E. and Jones, FD., Machinery's Handbook, 25th Edition, Industrial Press Inc., New York.

5.4 AAl, Aluminum Design Manual, Sixth Edition, The Aluminum Association Inc.

6.0

FINDINGS AND CONCLUSIONS

The down force calibrations stand is structurally adequate to support a design load of $5700 \mathrm{lb}$.

7.0 CALCULATIONS

7.1 Determine the weight of the Down Force Calibration Stand.

$$
\begin{aligned}
& \mathrm{V}_{0}:=12 \cdot \mathrm{in} \cdot 28.5 \cdot \mathrm{in} \cdot 1 \cdot \mathrm{in}-1 \cdot \mathrm{in} \cdot \frac{\pi}{4} \cdot(4.5 \cdot \mathrm{in})^{2} \quad \mathrm{~V}_{0}=326.096 \cdot \mathrm{in}^{3} \quad \text { Material volume of upper } 1 " \text { plate }(7) \\
& \mathrm{V}_{1}:=4 \cdot \mathrm{in} \cdot 4 \cdot \mathrm{in} \cdot 2.25 \cdot \mathrm{in}-1.75 \cdot \mathrm{in} \cdot \frac{\pi}{4} \cdot(2.75 \cdot \mathrm{in})^{2} \quad \mathrm{~V}_{1}=25.606 \mathrm{ein}^{3} \quad \text { Material volume of Push Block }(9) . \\
& \mathrm{V}_{2}:=6 \cdot \mathrm{in} \cdot 6 \cdot \mathrm{in} \cdot 2 \cdot \mathrm{in}-1 \cdot \mathrm{in} \cdot \frac{\pi}{4} \cdot(4.33 \cdot \mathrm{in})^{2}-1 \cdot \mathrm{in} \cdot\left[\frac{\pi \cdot(3 \cdot \mathrm{in})^{2}}{4}\right] \mathrm{V}_{2}=50.206 \cdot \mathrm{in}^{3} \quad \begin{array}{l}
\text { Material volume of Thrust } \\
\text { Bearing Block }(10) .
\end{array} \\
& V_{3}:=12 \cdot \mathrm{in} \cdot 28.5 \cdot \mathrm{in} \cdot .75 \cdot \mathrm{in}-4 \cdot .5 \cdot \mathrm{in} \cdot \frac{\pi}{4} \cdot(2.31 \cdot \mathrm{in})^{2} \quad V_{3}=248.118 \cdot \mathrm{in}^{3} . \text { Material volume of upper Pillow } \\
& \mathrm{V}_{4}:=10 \cdot \mathrm{in} \cdot 3 \cdot \mathrm{in} \cdot 2 \cdot \mathrm{in} \\
& \mathrm{V}_{4}=60 \cdot \mathrm{in}^{3} \quad \text { Material volume of air spring block (11). } \\
& \mathrm{V}_{5}:=28.4 \cdot \mathrm{in} \cdot \frac{\pi}{4} \cdot(1 \cdot \mathrm{in})^{2} \\
& \mathrm{~V}_{5}=22.305 \mathrm{ein}^{3} \quad \text { Material volume of Thompson rods (13). }
\end{aligned}
$$


HNF-3106, Rev. 0

Appendix A

$$
\begin{aligned}
& \mathrm{V}_{6}:=24 \cdot \mathrm{in} \cdot 3 \cdot \mathrm{in} \cdot 2 \cdot \mathrm{in} \\
& \mathrm{V}_{7}:=12 \cdot \mathrm{in} \cdot 28.5 \cdot \mathrm{in} \cdot 75 \cdot \mathrm{in}-4 \cdot .5 \cdot \mathrm{in} \cdot \frac{\pi}{4} \cdot(1.5 \cdot \mathrm{in})^{2} \\
& \mathrm{~V}_{8}:=2 \cdot \mathrm{in} \cdot .75 \cdot \mathrm{in} \cdot 4 \cdot \mathrm{in} \\
& \mathrm{V}_{9}:=\frac{\pi \cdot(1 \cdot \mathrm{in})^{2}}{4} \cdot 25.5 \cdot \mathrm{in} \\
& \mathrm{V}_{10}:=\frac{\pi \cdot(1.5 \cdot \mathrm{in})^{2}-(1.26 \cdot \mathrm{in})^{2}}{4} \cdot 40 \cdot \mathrm{in} \\
& \mathrm{V}_{11}:=\frac{\pi \cdot(.75 \cdot \mathrm{in})^{2}}{4} \cdot 11 \cdot \mathrm{in}
\end{aligned}
$$$$
V_{6}=144 \cdot i^{3}
$$$$
\mathrm{V}_{7}=252.966 \cdot \mathrm{in}^{3}
$$$$
V_{8}=6 \cdot \mathrm{in}^{3}
$$$$
\text { Material volume of Thompson }
$$$$
\text { rod supports (8). }
$$$$
\mathrm{V}_{9}=20.028 \cdot \mathrm{in}^{3}
$$$$
\text { Material volume of Axle (17). }
$$$$
\mathrm{V}_{10}=54.81 \mathrm{oin}^{3}
$$$$
\text { Material volume of Handle (15 and 16) }
$$$$
V_{11}=4.86 \mathrm{in}^{3} \quad \text { Material volume of Threaded Rod (45). }
$$

$$
\rho:=\left[\begin{array}{c}
.098 \\
.098 \\
.098 \\
.098 \\
.098 \\
.290 \\
.098 \\
.098 \\
.284 \\
.290 \\
.284 \\
.284
\end{array}\right] \cdot \frac{\mathrm{lbf}}{\mathrm{in}^{3}}
$$

Density of various components

Components with known weights.

$\mathrm{W}_{12}:=1 \cdot \mathrm{lbf}$

$\mathrm{W}_{13}:=1 \cdot \mathrm{lbf}$

$\mathrm{W}_{14}:=1 \cdot \mathrm{lbf}$

$\mathrm{W}_{15}:=16 \cdot \mathrm{lbf}$

$\mathrm{W}_{16}:=40 \cdot \mathrm{in} \cdot 8.27 \cdot \frac{\mathrm{lbf}}{\mathrm{ft}}$

$\mathrm{w}_{17}:=16 \cdot \mathrm{lbf}$

$\mathrm{W}_{18}:=1 \cdot \mathrm{lbf}$

$\mathrm{W}_{19}:=2 \cdot \mathrm{lbf}$
Weight of thrust bearing (23).

Weight of upper bearings (22).

Weight of lower bearings (21).

Weight of triple bellows air spring (28)

$\mathrm{W}_{16}=27.567 \cdot \mathrm{lbf}$

Weight of aluminum channel (12).

Weight of calibration scale (25).

Weight of swivel mount (27).

Weight of pneumatic wheels (24).
Individual weights of the various components. 
HNF-3106, Rev. 0

Appendix A

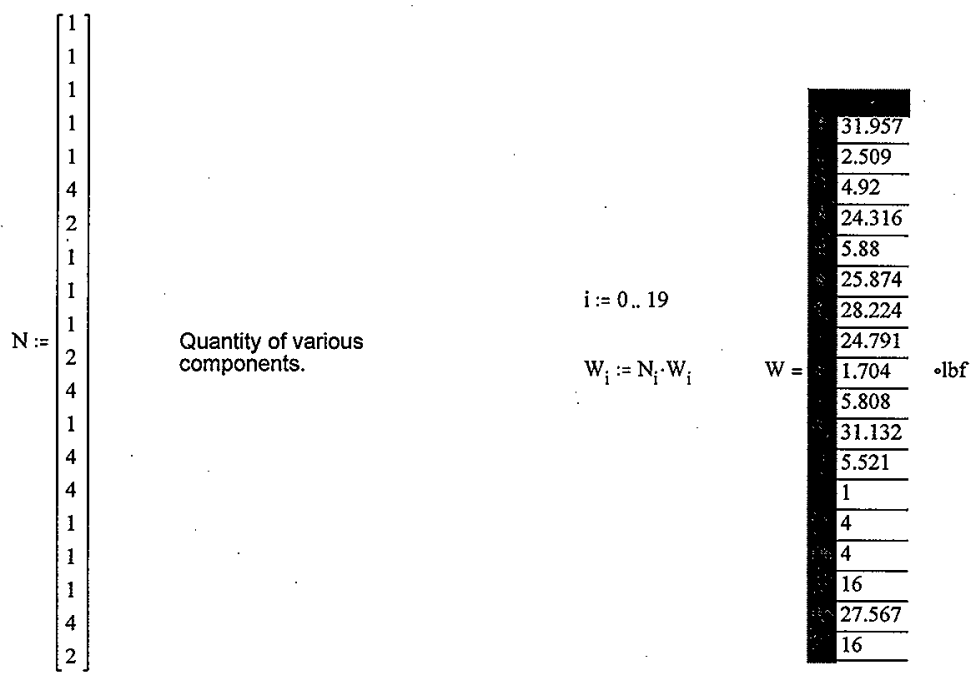

$\Sigma \mathrm{W}=269.203 \cdot \mathrm{lbf} \quad$ Total weight of components.

7.2 Determine the structural adequacy of the Down Force Calibration Stand given a maximum down force of $5700 \mathrm{lb}$.

$P:=5700 \cdot 1 b f$

7.2.1 Allowable stresses for material used in fabrication of Down Force Calibration Stand.

$\sigma_{y_{-} s s}:=30000 \cdot p s i$

$\sigma_{\text {b_ss }}:=.6 \cdot \sigma_{\text {y_ss }}$

$\tau_{\mathrm{ss}}:=.4 \cdot \sigma_{\mathrm{y}} \mathrm{ss}$

$\sigma_{\text {b_al }}:=28000 \cdot \mathrm{psi}$

$\tau_{\text {alum }}:=12000 \cdot$ psi

$\sigma_{y \_c s}:=36000 \cdot p s i$

$\sigma_{b_{-} \mathrm{cs}}:=.6 \cdot \sigma_{\mathrm{y}} \mathrm{cs}$

$\tau_{c s}:=.4 \cdot \sigma y_{-} c s$
Yield stress for 316L stainless steel, Machinery's Handbook 25, Page 440.

$\sigma_{\text {b_ss }}=18000$ opsi

Allowable bending stress per AISC 1989.

$\tau_{\mathrm{ss}}=12000 \circ \mathrm{psi}$

Allowable shear stress per AISC 1989.

Allowable bending stress for $6061-T 6$ aluminum

(AAl).

Allowable shear stress for $6061-T 6$ aluminum

(AAl).

Yield stress for piain carbon steel.

$\sigma_{b_{-} \mathrm{cs}}=21600 \cdot \mathrm{psi}$

Allowable bending stress per AISC 1989.

$\tau_{\text {cs }}=14400 \circ \mathrm{psi}$ 
Determine the allowable compressive stress for the Thomson rods.

$$
\begin{aligned}
& \mathrm{E}:=28 \cdot 10^{6} \cdot \mathrm{psi} \quad \text { Modulus of elasticity for stainless steel. } \\
& h:=26.5 \cdot \text { in Height of frame. } \\
& \mathrm{r}:=.5 \cdot \mathrm{in} \quad \text { Radius of Thomson rod. } \\
& \mathrm{A}_{\mathrm{c}}:=\pi \cdot(.5 \cdot \mathrm{in})^{2} \quad \mathrm{~A}_{\mathrm{c}}=0.785 \mathrm{oin}^{2} \quad \text {. Cross sectional area of Thomson rod. } \\
& k:=.65 \\
& \mathrm{C}_{\mathrm{c}}:=\sqrt{\frac{2 \cdot \pi^{2} \cdot \mathrm{E}}{\sigma_{\mathrm{y} \_s}}} \quad \mathrm{C}_{\mathrm{c}}=135.732
\end{aligned}
$$

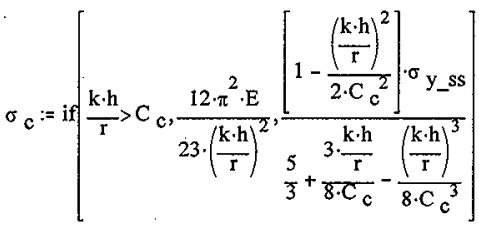

$$
\begin{aligned}
& \sigma_{\mathrm{c}}=16498.296 \text { opsi }
\end{aligned}
$$

Determine the maximum compressive stress on each column.

$$
\begin{aligned}
& \sigma_{c_{-} \text {actual }}:=\frac{P}{4 \cdot A_{c}} \quad \sigma_{c_{-} \text {actual }}=1814.364 \cdot \mathrm{psi} \quad \begin{array}{l}
\text { Actual maximum compressive force on the } \\
\text { columns. }
\end{array} \\
& \text { Answer }:=\text { if }\left(\sigma_{c} c_{\text {actual }} \leq \sigma_{c}, " O K ", \text { "No Good!" }\right) \quad \text { Answer }=\text { "OK" }
\end{aligned}
$$

Determine the adequacy of the bar fixing the base of each Thomson rod.
$h:=2 \cdot$ in
$w:=3 \cdot$ in
$b:=9 \cdot$ in
$\mathrm{L}:=17.5 \cdot \mathrm{in}$

Height and width of aluminum bar (PN 8).

Loaded width and effective length of aluminum bar, respectively.

$A_{c}:=w \cdot h$

Cross-sectional area of aluminum bar.

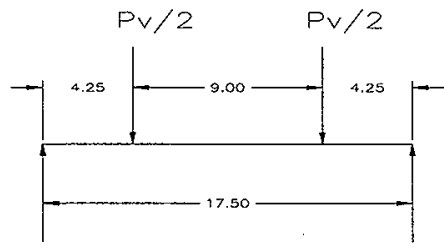

R1

$\mathrm{R} 2$
$a:=\frac{L-b}{2}$
$\mathrm{a}=4.25$ in

Distance from adjustable leg to Thomson rod (Note: $a=c$ ). 


$$
P_{V}:=\frac{P}{2}
$$

$$
P_{v}=2850 \cdot \mathrm{lbf}
$$

Maximum down force on a single bar.

Determine the maximum bending stress on the aluminum bar (PN 8).

$$
\begin{aligned}
& \mathrm{M}_{\max }:=\left(\frac{P \cdot v}{2}\right) \cdot \mathrm{a} \quad \mathrm{M}_{\max }=6056.25 \text { in } \cdot \mathrm{lbf} \quad \text { Maximum moment in the bar. } \\
& \mathrm{S}_{\text {bar }}:=\frac{\mathrm{w} \cdot \mathrm{h}^{2}}{6} \quad \mathrm{~S}_{\text {bar }}=2 \cdot \mathrm{ein}^{3} \quad \text { Section moduitus of the bar. } \\
& \sigma_{\text {bar }}:=\frac{M_{\max }}{S_{\text {bar }}} \quad \sigma_{\text {bar }}=3028.12 \circ \mathrm{psi} \quad \text { Maximum bending stress on the bar. } \\
& \text { Answer }:=\text { if }\left(\sigma_{\text {bar }}<\sigma_{\text {b_al }} \text {, "OK" , "No Good!" }\right) \quad \text { Answer }=\text { "OK" }
\end{aligned}
$$

Determine the maximum shear stress on the bar.

$$
\begin{gathered}
\tau_{\text {bar }}:=\frac{\frac{P_{v}}{2}}{\frac{A_{c}}{T_{c}}} \\
\tau_{\text {alum }}:=12000 \cdot \mathrm{psi}
\end{gathered}
$$

Maximum shear stress on the bar.

7.3 Determine the adequacy of the 4 legs used to level the stand.

$$
\begin{array}{ll}
\mathrm{K}:=2 & \text { Effective length factor. } \\
\mathrm{D}:=.627 \cdot \mathrm{in} & \text { Min. root diameter for } 3 / 4 \text { in all thread. } \\
\mathrm{L}:=7 \cdot \text { in } & \text { Length of all thread Item No } 45 . \\
\mathrm{r}:=\frac{\mathrm{D}}{2} & \mathrm{r}=0.314 \text { oin } \\
\mathrm{E}:=29 \cdot 10^{6} \cdot \mathrm{psi} & \text { Modulus of elasticity for carbon steel. } \\
\sigma_{\mathrm{y}_{-} \mathrm{cs}}:=36 \cdot 10^{3} \cdot \mathrm{psi} & \text { Yield stress of carbon steel. }
\end{array}
$$

Determine the allowable compressive stress for the $3 / 4$ in. all thread per AISC 1989.

$$
\frac{\mathrm{K} \cdot \mathrm{L}}{\mathrm{r}}=44.657 \quad \text { Slenderness Ratio. }
$$

$$
C_{c}:=\sqrt{\frac{2 \cdot \pi^{2} \cdot E}{\sigma_{y_{-} c s}}} \quad C_{c}=126.099
$$

$$
\sigma_{c}:=\operatorname{if~}\left[\frac{\mathrm{K} \cdot \mathrm{L}}{\mathrm{r}}>\mathrm{C}_{\mathrm{c}}, \frac{12 \cdot \pi^{2} \cdot \mathrm{E}}{23 \cdot\left(\frac{\mathrm{K} \cdot \mathrm{L}}{\mathrm{r}}\right)^{2}}, \frac{\left[1-\frac{\left(\frac{\mathrm{K} \cdot \mathrm{L}}{\mathrm{r}}\right)^{2}}{2 \cdot \mathrm{C}_{\mathrm{c}}{ }^{2}}\right] \cdot \sigma_{\mathrm{y}_{-} \mathrm{cs}}}{\frac{5}{3}+\frac{3 \cdot \frac{\mathrm{K} \cdot \mathrm{L}}{\mathrm{r}}}{8 \cdot \mathrm{C}_{\mathrm{c}}}-\frac{\left(\frac{\mathrm{K} \cdot \mathrm{L}}{\mathrm{r}}\right)^{3}}{8 \cdot \mathrm{C}_{\mathrm{c}}^{3}}}\right] \quad \sigma_{\mathrm{c}}=18809.385 \cdot \mathrm{psi}
$$


Determine the actual compressive stress.

$\begin{array}{ll}A_{c}:=.334 \cdot \mathrm{in}^{2} & \text { Cross sectional area of } 3 / 4 \text { in all thread (AISC } \\ 1989) .\end{array}$

$\sigma_{\mathrm{a}}:=\frac{\frac{P+200 \cdot \mathrm{lbf}}{4}}{A_{\mathrm{c}}}$

Actual compressive stress.

$$
\text { Answer : }=\text { if }\left(\sigma_{a}<\sigma_{c}, \text { "OK", "No Good!" }\right) \quad \text { Answer }=\text { "OK" }
$$

7.5 Determine the adequacy of Hex HD Screws (PN 39 \& 40) connecting a Thomson rod (PN13) to either the Upper Rod Plate (PN 7) or Lower Rod Position Bar (PN 8) and Base Channel (PN 12).

$\sigma_{\text {y_grade } 5}:=92 \cdot 10^{3} \cdot \mathrm{psi} \quad$ Yield stress of SAE grade 5 screws (ref. Oberg, E.)

$\sigma_{t_{\text {_allow }}}:=.6 \cdot \sigma_{\mathrm{y}_{\text {_gades }}} \quad$ Allowable tensile stress per AISC 1989.

$A_{k}:=.126 \cdot i^{2} \quad$ Min root area for a $1 / 2$ in screw (AISC 1989).

$\mathrm{d}:=.5 \cdot$ in $\quad$ Distance from center of bolt to edge of rod.

$\sigma_{t}:=\frac{\frac{P}{4}}{A_{k}} \quad \sigma_{t}=11309.507$ opsi Maximum tensile stress on a single screw due to prying and downforce.

$$
\text { Answer }:=\text { if }\left(\sigma_{t}<\sigma_{t} \text { allow }, \text { "OK", "No Good!" }\right) \quad \text { Answer }=\text { "OK" }
$$

7.6 Determine the adequacy of the Handles (PN $15 \& 16$ ).

\subsubsection{Force on Handle.}

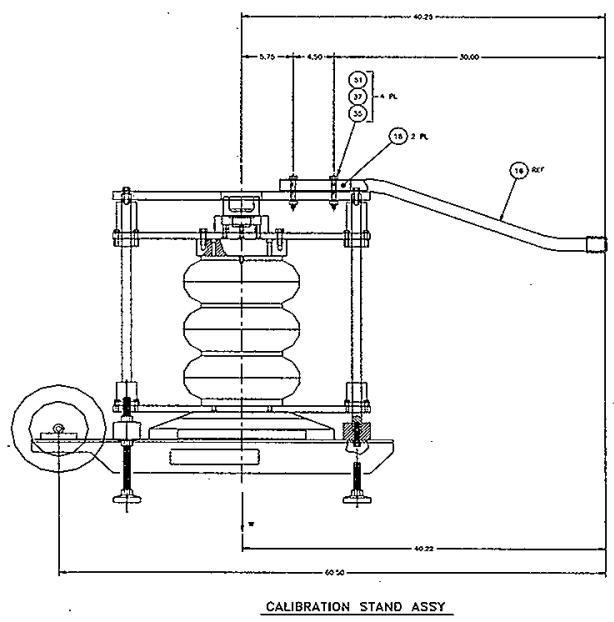

A-8 


$$
d_{1}:=60.5 \cdot \text { in } \quad d_{2}:=60.5 \text { in }-40.22 \cdot \text { in }
$$

$F_{\text {handle }}:=\frac{\frac{\Sigma W}{2} \cdot d_{2}}{d_{1}} \quad F_{\text {handle }}=45.119 \cdot \mathrm{lbf} \quad$ Actual force on a single handle.
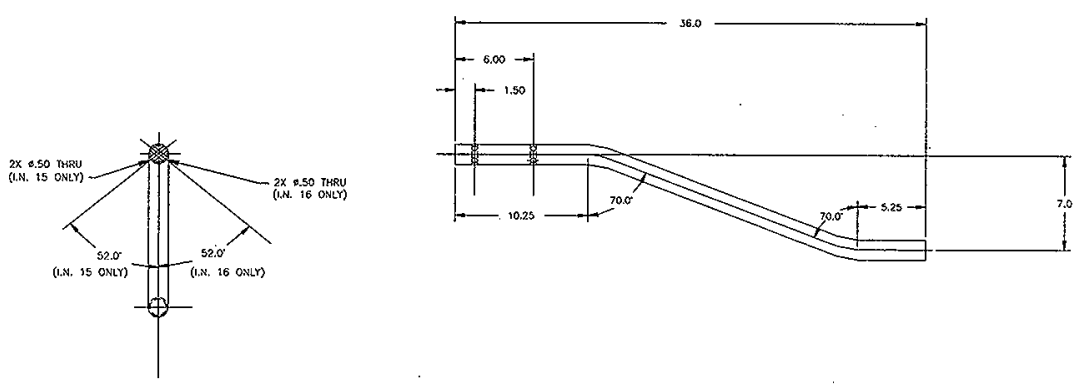

Determine the stresses on the handle.

$$
\begin{aligned}
& \mathrm{T}:=\mathrm{F}_{\text {handle }} \cdot \mathbf{7 \cdot \mathrm { in }} \\
& \mathrm{T}=315.835 \text { in } \cdot 1 \mathrm{bf} \\
& \mathrm{A}=\mathrm{t} .496 \cdot \mathrm{in}^{2} \\
& \text { Maximum torque on handie. } \\
& \mathrm{A}:=\frac{\pi \cdot(1.5 \cdot \mathrm{in}-.12 \cdot \mathrm{in})^{2}}{4} \\
& \text { Thickness of tubing. } \\
& \mathbf{t}:=.12 \cdot \text { in } \\
& \tau_{\mathrm{T}}=879.832 \cdot \mathrm{psi} \\
& \text { Maximum torsional shear stress on a handle. } \\
& \tau_{\mathrm{T}}:=\frac{\mathrm{T}}{2 \cdot \mathrm{t} \cdot \mathrm{A}} \\
& \mathrm{A}_{\mathrm{c}}:=\frac{\pi \cdot\left[(1.5 \cdot \mathrm{in})^{2}-(1.5 \cdot \mathrm{in}-.24 \cdot \mathrm{in})^{2}\right]}{4} \\
& \mathrm{~A}_{\mathrm{c}}=0.52 \cdot \mathrm{in}^{2} \\
& \text { Cross sectional area of } 1.5^{\prime \prime} \text { tubing. } \\
& \tau_{V}:=\frac{F_{\text {handle }}}{A_{c}} \\
& { }^{\tau_{V}}=86.726 \cdot \mathrm{psi} \\
& \tau:=\tau T+\tau \mathrm{V} \\
& \tau=966.558 \text { opsi } \\
& \text { Answer := if }(\tau<\tau \text { cs, "OK", "No Good!" }) \\
& \text { Answer }=\text { "OK" } \\
& \mathrm{M}:=30 \cdot \mathrm{in} \cdot \mathrm{F} \text { handle } \\
& M=1353.577 \cdot \mathrm{in} \cdot \mathrm{lbf} \\
& \text { Maximum moment on handle. } \\
& S:=\frac{\pi \cdot\left[(1.5 \cdot \mathrm{in})^{4}-(1.25 \cdot \mathrm{in})^{4}\right]}{32 \cdot 1.5 \cdot \mathrm{in}} \quad S=0.172 \mathrm{oin}^{3} \\
& \sigma_{b}:=\frac{M}{S} \\
& \sigma_{\mathrm{b}}=7890.257 \cdot \mathrm{psi} \\
& \text { Answer : }=\text { if }\left(\sigma_{b}<\sigma_{b} \text { cs }, \text { "OK", "No Good!" }\right) \quad \text { Answer }=\text { "OK" }
\end{aligned}
$$


HNF-3106, Rev. 0

Appendix A

Determine the stress on the CS $12 \times 8.27$
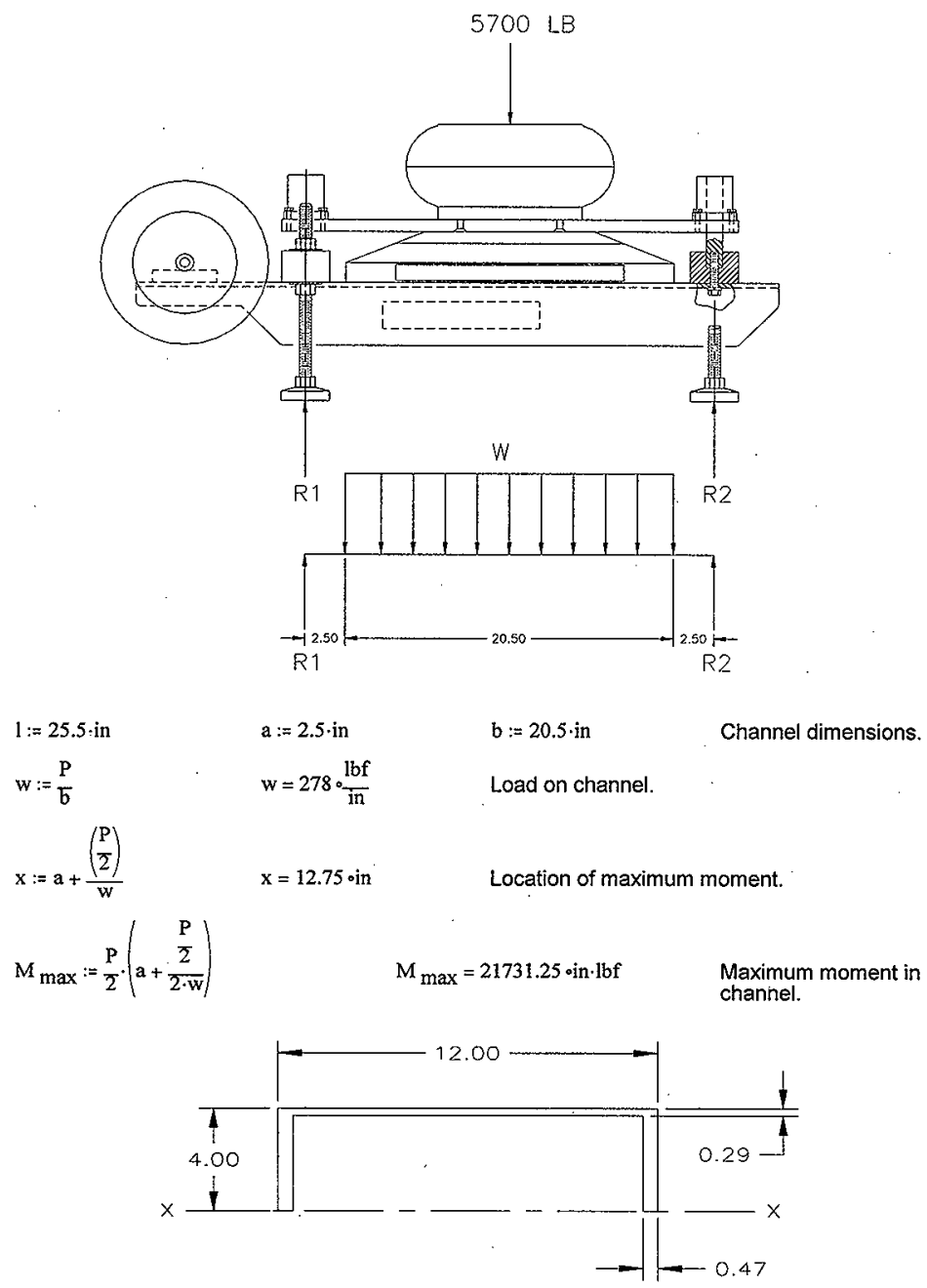
HNF-3106, Rev. 0

Appendix A

$$
\begin{aligned}
& A_{\mathrm{fl}}:=.47 \cdot \mathrm{in} \cdot(4 \cdot \mathrm{in}-.29 \cdot \mathrm{in}) \\
& \mathrm{A}_{\mathrm{fl}}=1.744 \cdot \mathrm{in}^{2} \quad \text { Area of flange. } \\
& \mathrm{A}_{\mathrm{W}}:=.29 \cdot \mathrm{in} \cdot 12 \cdot \mathrm{in} \\
& \mathrm{A}_{\mathrm{w}}=3.48 \cdot \mathrm{in}^{2} \quad \text { Area of web. } \\
& A_{\text {total }}:=2 \cdot A_{f l}+A_{W} \\
& A_{\text {total }}=6.967 \cdot \mathrm{in}^{2} \quad \text { Total Area } . \\
& \text { Ybar fl }_{\text {f }}=\frac{(4 \cdot \mathrm{in}-.29 \cdot \mathrm{in})}{2} \\
& \operatorname{Ybar}_{\mathrm{fl}}=1.855 \text { oin } \quad \text { Distance from } \mathrm{X}-\mathrm{X} \text { to } \mathrm{CG} \text { of flange. } \\
& \operatorname{Ybar}_{\mathrm{w}}:=4 \cdot \mathrm{in}-\frac{.29 \cdot \mathrm{in}}{2} \\
& \operatorname{Ybar}_{\mathrm{W}}=3.855 \text { in } \quad \text { Distance from } X-X \text { to } C G \text { of web. }
\end{aligned}
$$

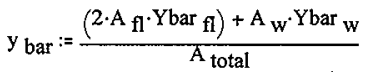

$$
\begin{aligned}
& \mathrm{y}_{\text {bar }}=2.854 \text { oin } \\
& \text { Distance to } C G \text { of channel from } X-X \text {. } \\
& \mathrm{d}_{\mathrm{fl}}:=\mathrm{y}_{\mathrm{bar}}-\left(\frac{4 \cdot \mathrm{in}-.29 \cdot \mathrm{in}}{2}\right) \\
& \mathrm{d}_{\mathrm{ft}}=0.999 \cdot \mathrm{in} \\
& \mathrm{d}_{\mathrm{w}}:=\left(4 \cdot \mathrm{in}-\frac{.29 \cdot \mathrm{in}}{2}\right)-\mathrm{y}_{\text {bar }} \\
& d_{w}=1.001 \text { in } \\
& \mathrm{I}_{\mathrm{W}}:=\frac{12 \cdot \mathrm{in} \cdot(.29 \cdot \mathrm{in})^{3}}{12} \\
& I_{w}=0.024 \sin ^{4} \\
& \begin{array}{l}
\text { Distance from CG of flange to CG } \\
\text { of channel. }
\end{array} \\
& \mathrm{I}_{\mathrm{fl}}:=\frac{.47 \cdot \mathrm{in} \cdot(4 \cdot \mathrm{in}-.29 \cdot \mathrm{in})^{3}}{12} \\
& I_{f I}=2 \cdot \operatorname{in}^{4} \\
& \text { Distance from CG of web to CG of } \\
& \text { channel. } \\
& \text { Moment of inertia of web. }
\end{aligned}
$$

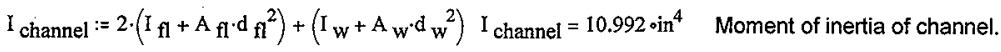

$$
\begin{aligned}
& \sigma_{\text {channel }}:=\frac{M_{\max } \frac{y_{\text {bar }}}{2}}{I_{\text {channel }}} \\
& \sigma_{\text {channel }}=2821.158 \text { psi Maximum bending stress in the } \\
& \text { Answer }:=\text { if }\left(\sigma_{\text {channel }}^{<\sigma_{b} \text { al }}, \text { "OK", "No Good!" }\right) \quad \text { Answer }=\text { "OK" }
\end{aligned}
$$

